\title{
Traditional Chinese Medicine: An Opportunity for Discovery
}

Traditional Chinese medicine (TCM) is a 3000-year-old holistic system of medicine combining the use of herbs, acupuncture, dietary therapy, massage, and therapeutic exercise. TCM is largely based on the philosophical concept that the human body is a small universe with a set of complete and sophisticated interconnected systems, and that these systems usually work in harmony to maintain the healthy functions of the body.

TCM has a unique model of the body. Unlike the Western model, which divides the physical body into anatomical parts, the TCM model is more concerned with function. TCM divides the body into functional parts that happen to have the same names as the Western anatomical parts. For example, the TCM spleen is not a specific piece of flesh but an aspect of function related to transformation and transportation within the body and of the mental functions of thinking and studying.

There is still another major difference between TCM and Western medicine: TCM deals with the host and Western medicine deals with the disease. TCM establishes a diagnosis of the individual, rather than the disease, using a process called syndrome identification, whereby the practitioner makes a dynamic conceptualization of the individual's situation and comes up with a pathophysiologic status (the type of disharmony) for the individual; this status is called zheng, or syndrome. The therapeutics used to restore the harmony within the host and between the host and the host's environment are determined by the identified syndrome. The theory of TCM diagnosis and management has not been elucidated in Western scientific terms. However, if the TCM syndrome identification process works, there may be scientific reasons to explain it.

Although the TCM theories and practice are markedly different from the thinking of Western medicine, there are compelling reasons why we should no longer ignore TCM.

First, over the last 10 years, complementary and alternative medicine (CAM) practice has gained popularity in Western society. This has led the World Health Organization to publish its Traditional Medicine Strategy 2002-2005 ${ }^{1}$, and the White House Commission to publish its Complementary and Alternative Medicine Policy ${ }^{2}$. Both these documents addressed policies about the efficacy, quality, and rational use of CAM. In addition, the US National Institutes of Health has established a National Center for Complementary and Alternative Medicine to study this area ${ }^{3}$. TCM is the most commonly used of all the CAM disciplines. According to Rao, et al, of the $60 \%-90 \%$ of patients with arthritis who have used CAM, most used TCM ${ }^{4}$. Although the exact num- ber of people who use TCM in the United States is unknown, it was estimated in 1997 that some 10,000 practitioners served more than 1 million patients each year ${ }^{5}$. According to the 2007 National Health Interview Survey, which included questions on the use of various CAM therapies, an estimated 3.1 million US adults had used acupuncture in the previous year ${ }^{5}$. While the number of people using TCM in Canada is not available, one would imagine that the situation in Canada would be similar to that in the US. The Ontario Government estimates there were between 3000 and 4000 practitioners of TCM and acupuncture in the province $^{6}$. As more of our patients seek TCM care, it behooves us to understand TCM to be able to advise and safeguard our patients appropriately.

Second, over the last 50 years, significant changes to TCM have occurred in China. Currently there are at least 6 TCM universities in China, all offering postgraduate degrees, more than 20 community colleges, and more than $50 \mathrm{sec}-$ ondary TCM schools. The Chinese Ministry of Education has established a uniform curriculum for all TCM institutions. A registration system is now in place in China to regulate TCM practitioners. The Chinese government has also begun to regulate the TCM herbs and drugs and has established criteria for agricultural practice, laboratory practice, manufacturing practice, and clinical practice for the pharmaceutical industry. There are over 100 TCM journals currently in print in China. Clinical research data are published in these journals. In British Columbia, through the Health Professions Act, the College of Traditional Chinese Medicine Practitioners and Acupuncturists of British Columbia (CTCMA) was established in 2000. CTCMA is an official professional licensing authority to regulate the practice of TCM and acupuncture in the province. As of April 2003, all TCM practitioners and acupuncturists in British Columbia must be licensed. On December 20, 2006, Ontario became the second Canadian province to regulate TCM. Thus, TCM is accepted as a legitimate healthcare system in China and in the provinces of British Columbia and Ontario in Canada. It is our responsibility to evaluate TCM, if for no other reason than to ensure that our patients receive benefit and not harm.

Third, Western medicine has served mankind well. In the field of rheumatology, ever since the increasing elucidation of immune mechanisms and the development of transplantation biology, we have gained much insight into the pathophysiology and treatment of rheumatic diseases. Nevertheless, despite all these advances over recent decades, we still have difficulties understanding the precise etiology and

Personal non-commercial use only. The Journal of Rheumatology Copyright @ 2010 . All rights reserved. 
pathogenesis of these diseases, let alone managing and curing them. Holman stated 3 possible barriers to the understanding of the rheumatic diseases": (1) the "single lesion" perception of disease causation that has been derived from infectious disease; (2) the dominance of the concept of "acute disease," that pathogenic processes arise abruptly and can be reversed abruptly; and (3) the investigative strategy of reductionism, which seeks to study isolated reactants in order to understand true basic processes devoid of confounding interactions. Revising our thinking processes and looking to other disciplines may permit us to progress in our conceptualizations and change research and treatment directions. As Walter Lippman stated, "Where all think alike, no one thinks very much."

However, such discussion will have little practical consequence if steps are not taken to approach these issues. Accordingly, we suggest that the initial approach for TCM should be to evaluate this area in an organized, critical fashion, to determine its clinical efficacy. If TCM is found to have no clinical efficacy, there is no need to look into it further. But to establish TCM clinical efficacy requires an innovative approach. The randomized, controlled clinical trial is considered to be the methodology offering the highest level of evidence. However, as pointed out by Pincus and Tugwell ${ }^{8}$, different types of research are needed to answer different types of clinical questions. Observational studies and case reports often are the only research method suitable for certain clinical research. TCM efficacy research is one of them. TCM is holistic and conceptual, and it identifies and treats syndromes rather than diseases. The interventions of TCM tend to involve multiple, interactive measures, and its outcomes tend to depend on whether harmony is restored, all of which make measurement difficult ${ }^{9}$.

While clinical research on TCM has been conducted in China and the West, much of this research was inadequate in delivering reliable data. In 2008, a review of a total of 70 Cochrane systematic reviews regarding TCM clinical research found most of the studies to be inconclusive ${ }^{10}$. Reasons were multiple. However, most of these projects employed randomized controlled designs that were not suitable for TCM research, and most of the research had not involved collaboration between Western and TCM scientists. Thus, there was a failure to consider the fundamental concepts of TCM in terms of diagnosis. Moreover, the measures of efficacy derived from Western views of disease (disease endpoint) did not consider the goals of TCM (syndrome endpoint). It is important to incorporate the concepts of both Western medicine and TCM into research protocols, necessitating collaboration between Western and TCM practitioners ${ }^{9}$.

We propose that rheumatologists take the lead in establishing a working relationship with the leading TCM universities in China, to combine their expertise in TCM with our expertise in the Western diagnosis and evaluation of rheumatic diseases and conduct of clinical studies, and to develop research projects. Such projects could assess whether TCM is effective and safe as an alternative or complementary approach in managing rheumatic disease. Within such collaboration, Western rheumatic disease diagnoses could be "selected out" from the TCM syndromes and outcomes evaluated by established Western assessment instruments, with the only "blinding" being that the TCM practitioner would treat in his or her usual fashion and the independent assessor would only evaluate specific outcome measures. The least outcome would be to find that TCM interventions are without value. The most exciting would be to find that not only do they have value, but that this realization offers new therapies and hypotheses of illness.

We conclude with one of Confucius's teachings, which translates as, "The stone at the other mountain, with careful polish, may turn out to be jade."

\author{
IAN K. TSANG, MB, FRCPC, \\ Division of Rheumatology, \\ University of British Columbia; \\ Visiting Professor, \\ Guangzhou University for Traditional Chinese Medicine, \\ Guangdong, China; \\ SIMON H. HUANG, MD, FRCPC; \\ BARRY E. KOEHLER, MD, FRCPC, \\ Division of Rheumatology, \\ University of British Columbia, \\ Vancouver, BC, Canada
}

Address correspondence to Dr. Tsang; E-mail: itsang@arthritisresearch.ca

\section{REFERENCES}

1. World Health Organization. WHO Traditional Medicine Strategy 2002-2005. [Internet. Accessed June 10, 2010.] Available from: http://whqlibdoc.who.int/hq/2002/WHO_EDM_TRM_2002.1.pdf

2. White House Commission on Complementary and Alternative Medicine Policy. Final report, March 2002. [Internet. Accessed June 10, 2010.] Available from: http://www.whccamp.hhs.gov/ finalreport.html

3. National Center for Complementary and Alternative Medicine. Expanding horizons of health care: strategic plan, 2005-2009. [Internet. Accessed June 10, 2010.] Available from:http://nccam.nih.gov/about/plans/2005/

4. Rao JK, Mihaliak K, Kroenke K, Bradley J, Tierney WM, Weinberger M. Use of complementary therapies for arthritis among patients of rheumatologists. Ann Intern Med 1999;131:409-16.

5. National Center for Complementary and Alternative Medicine. Traditional Chinese medicine: an introduction. [Internet. Accessed June 10, 2010.] Available from: http://nccam.nih.gov/health/ whatiscam/chinesemed.htm

6. MacKay B. New Ontario college for traditional Chinese medicine. CMAJ 2007;176:435-6.

7. Holman H. Thought barriers to understanding rheumatic diseases. Arthritis Rheum 1994;37:1565-72.

8. Pincus T, Tugwell P. Shouldn't standard rheumatology clinical care be evidence-based rather than eminence-based, eloquence-based, or elegance-based? J Rheumatol 2007;34:1-4.

9. Tsang IK. Establishing the efficacy of traditional Chinese medicine. Nat Clin Pract Rheumatol 2007;3:60-1.

10. Manheimer E, Wieland S, Kimbrough E, Cheng K, Berman BM. Evidence from the Cochrane Collaboration for Traditional Chinese Medicine therapies. J Altern Complement Med 2009;15:1001-14.

J Rheumatol 2010;37:1989-90; doi: 10.3899/jrheum.100227 Personal non-commercial use only. The Journal of Rheumatology Copyright @ 2010 . All rights reserved. 